\title{
ANXIETY, DEPRESSION AND PERSONALITY TYPES IN PATIENTS WITH INFLAMMATORY BOWEL DISEASE: COMPARISONS WITH PEPTIC ULCER AND THE GENERAL POPULATION
}

\author{
Emil Babić ${ }^{1}$, Milenko Bevanda ${ }^{1}$, Maja Karin ${ }^{1}$, Mile Volarić ${ }^{1}$, Ante Bogut ${ }^{1}$, \\ Daniela Bevanda Glibo ${ }^{1}$, Danijel Bevanda ${ }^{1} \&$ Nikica Šutalo ${ }^{2}$ \\ ${ }^{I}$ University of Mostar Clinical Hospital, Department of Gastroenterology and Hepatology, \\ Mostar, Bosnia and Herzegovina \\ ${ }^{2}$ University of Mostar Clinical Hospital, Department of Psychiatry, Mostar, Bosnia and Herzegovina
}

received: 28.8.2018;

revised: 22.2.2019;

accepted: 2.4 .2019

\section{SUMMARY}

Aim: To explore corellation of anxiety, depression ant type of personality in inflammatory bowel disease (IBD) and compare with peptic ulcer $(P U)$.

Subjects and methods: In this study, prevalence of anxiety, depression and type of personality was investigated in 362 cases divided into three groups: 112 of IBD patients, 122 of peptic ulcer patients and 128 of control group who didn't have any gastrointestinal or psychic complaints. IBD and peptic ulcer diagnosis were established by standard diagnostic procedures (anamnesis, clinical manifestations, laboratory, endoscopy and biopsy in IBD and upper endoscopy in peptic ulcer). Anxiety and depression were established by Hamilton anxiety rating scale (HAM-A) and Hamilton rating test for depression (HAM-D). Type of A/B personality was established by Bortner scale and D type of personality by Denollet scale (DS14).

Results: Anxiety was found in 47 (41.9\%) and depression in 44 (38.3\%) of a total of 112 IBD cases. In group with peptic ulcer anxiety was found in 40 (32.8\%) and depression aalso in 40 (32.8\%) of total 122 cases. In control group anxiety was diagnosed in 21 (16.4\%) and depression in 20 (15.6\%) of total 128 cases. Anxiety and depresson were significantly higher in both groups than in control group but anxiety and depression were significantly higher in IBD group than peptic ulcer group. D type of personality was statistically significant in peptic ulcer group.

Conclusion: Anxiety and depression in IBD and peptic ulcer cases have a greater prevalence compared to the normal population and surprisingly are higher in IBD than peptic ulcer group. D type of personality is associated with peptic ulcer.

Key words: inflammatory bowel disease - peptic ulcer - anxiety - depression - A/B type of personality - D type of personality Bortner scale - Denollet test

\section{INTRODUCTION}

Access to the patient is today very often a partial view of the large number of specialty and subspecialty. Often doctors observed patients solely from the angle of their own specialization without taking into account that the patient is a complex entity, with all its somatic and psychological characteristics. This is the reason why more and more often speak about "holistic" approach to the patient, taking into account the interaction of psychic and somatic symptoms and signs (Jakovljević 2015). Clinical practice shows that the simultaneous presence of several pathological conditions in the form of comorbidity and multimorbidity is more often the rule than the exception. Comorbidity indicates the simultaneous existence of two or more medical conditions which are interconnected with the pathogenetic mechanism (Jakovljević 2013). Studies on anxiety and depression in inflammatory bowel disease (IBD) yielded inconsistent results. There were inconsistent results if the amount of anxiety and depression were higher in IBD patients than in controls with chronic somatic diseases (Mikocka-Walus 2007).

The authors stated that the controversies on anxiety and depression in IBD can be due inadequate control for disease activity and lack of adequately matched control groups in most studies. There were inconstinent results about different levels of anxiety and depression in Crohn's disease (CD) and ulcerative colitis (UC) (Mikocka-Walus 2007).Another open question are the significance of gender, sociodemographic, social class and education level in anxiety and depression in IBD (Porcelli 1996). Recent systematic reviews on the role of depression and anxiety in inflammatory bowel disease suggest that real impact of disease activity on anxiety and depression has to be tested in future (Graff 2009). There is not enough studies about type of personality in IBD. A variety of personality traits and psychological symptom states have been reported to be associated with some gastrointestinal disease.

The aims of our study were: 1) to established prevalence and level of anxiety and depression in IBD 2) to investigate possible correlation between level of disease activity (clinical and endoscopic) with anxiety and depression 3) to compare anxiety and depression of IBD patients with an adequately matched sample of the general population and peptic ulcer patients 4) to investigate correlation of personality types in IBD and peptic ulcer, 5) to explore and compare the potential impact of gender and sociodemographic variables on anxiety and depression in IBD and peptic ulcer patients. 


\section{SUBJECTS AND METHODS}

\section{Subjects}

There were 362 participants divided in to 3 groups:

1) IBD group (112 patients),

2) peptic ulcer group (122 patients) and

3) general population group (128 participants).

\section{IBD Patients}

Consecutive adult patients ( $>18$ years) with a diagnosis of Crohn's disease (CD) or ulcerative colitis (UC), confirmed by endoscopy and histology, attending Clinic of gastroenterology at Universitiy Clinic Hospital Mostar, Bosnia and Herzegovina, were offered to participate in this study. There were a total of 112 adults who had attended our Clinic and IBD ambulance at least once between July 2013 and October 2015 with a confirmed diagnosis of either $\mathrm{CD}$ or UC. Each of these patients were determined clinic and endoscopic IBD activity, separately for CD and UC. Disease activity in $\mathrm{CD}$ was measured by the CDAI (Crohn's disease activity index) and SES-CD (Endoscopic Crohn Disease Index). Disease activity in UC was measured by the Truelove \&Witts scale and Baron endoscopic index.

Each of these patients was asked to complete questionnaires for anxiety and depression scale, Hamilton anxiety rating scale (HAM-A) and Hamilton rating test for depression (HAM-D).

Patients also completed questionnaires for type of personality - A/B personality type (Bortner test) and D personality type (Denollet test). Patients are analized by gender, sex, duration of disease and level of education. The impact of disease activity on anxiety and depression were analized and compared with sociodemographic variables (gender, sex, duration of disease and level of education).

\section{Peptic ulcer patients}

There were 122 peptic ulcer (PU) patients, 22 patients with stomach and 100 with duodenal ulcer. Diagnosis was established by endoscopy in our cabinet. All patients with diagnosis of peptic ulcer were asked to complete questionnaires for anxiety and depression scale (HAM-A and HAM-D) and for type of personality - A/B personality type (Bortner test) and D personality type (Denollet test).

\section{General population}

A representative sample of the general population was selected in medical staff and volunteers who didn't have any proven gastrointestinal or psychiatric diseases. There were 128 participants, 71 women and 57 men. All of them were asked to complete questionnaires for anxiety and depression s (HAM-A and HAM-D) and type of personality (Bortner and Denollet test).

\section{Disease activitiy indexes in IBD}

The Crohn's Disease Activity Index or CDAI is used to quantify the symptoms of patients with Crohn's disease. The index consists of eight factors, each summed after adjustment with a weighting factor. Remission of Crohn's disease is defined as CDAI below 150. Severe disease was defined as a value of greater than 450. Most major research studies on medications in Crohn's disease define response as a fall of the CDAI of greater than 70 points.

The Simple Endoscopic Score (SES-CD) validated endoscopic activity in CD. Endoscopic parameters (ulcer size, ulcerated and affected surfaces, stenosis) were scored from 0 to 3 and analized for the five bowel segments. Remission is defined as SES-CD below 3, 410 mild, 11-19 moderate and $>20$ as a severe disease.

UC clinical activity is based on the Truelove and Witts' severity index. The Truelove and Witts' criteria includes bowel movements, pyrexia, pulse rate, anaemia and erythrocyte sedimentation rate. The severity of UC is classifed as mild, moderate and severe.

Baron score is used for grading the endoscopic severity of ulcerative colitis, with 0 being normal and 1-3 of increasing severity based on a haemorrhagic appearence of the mucosa and its response to light touch.

\section{Questionnaires}

HAM-A consists of 14 items, each defined by a series of symptoms, and measures both psychic anxiety (mental agitation and psychological distress) and somatic anxiety (physical complaints related to anxiety). Each item is scored on a scale of 0 (not present) to 4 (severe), with a total score range of $0-56$, where $<17$ indicates mild severity, 18-24 mild to moderate severity and 25-30 moderate to severe. HAM-D consists of 17 items and was designed for adults and used to rate the severity of their depression by probing mood, feelings of guilt, suicide ideation, insomnia, agitation or retardation, anxiety, weight loss and somatic symptoms. Each item on the questionnaire is scored on a 3 or 5 point scale. A score of 0-7 is considered to be normal. Scores of 8-13 indicate mild depression, 14-18 moderate depression, 19-22 severe depression and $\geq 23$ very severe depression.

Bortner scale for type A/B personality contained of 14 items. Each constinting of two phrases placed at opposite ends and phrases are on the contrary. Respondents were asked to place a vertical mark through a 1.5 inch line seperating the two phrases to indicate their position between the two extremes. Result under 84 ponts represents type B personality and above 84 points type A personality. Type A and type B personality are two contrasting personality types. Type A personality is more competitive, outgoing, ambitious, impatient and aggressive while type B personality is more relaxed.

Denollet test contained 14-item questionnaire, seven items refer to negative affectivity and seven items refer to social inhibition. People who score 10 points or more on both dimensions are classified as Type D. Type D personality have the tendency to experience increased negative emotions across time and situations and tend not to share these emotions with others, because of fear of rejection or disapproval. 


\section{RESULTS}

\section{Anxiety and depression in IBD}

In the total of 112 IBD patient, anxiety were found in $47(41.9 \%)$ and depression in $44(39.3 \%)$ patients. When the patients with $\mathrm{CD}$ and UC were analised separately, prevalence of anxiety in CD was $44.1 \%$ and depression $48.8 \%$. Prevalence of anxitey in UC was $40.6 \%$ and depression $33.3 \%$ (Table 1 ).

There were no significant differences between CD and UC patients in the anxiety and depression scale (Table 2).

When analized level of anxiety and depression, the most of CD anxious patients had severe level of anxiety, 11 patients $(25.6 \%)$. CD patients with depression had the most mild level of depression, 11 patients $(25.6 \%)$. The most of UC patients with anxiety had moderate level of anxiety, 11 patients $(15.9 \%)$. UC patients with depression had the most mild level of depression, 10 patients (14.5\%) (Table 3$)$.

The levels of anxiety and depression of CD and UC patients were correlated with disease activity and there was no difference between clinical and endoscopic indexes. Anixiety and depression was strong associated with disease activity (Table 4).

The higher level of anxiety was found in IBD patients with lower education level. The levels of anxiety and depression of IBD patients did not differ after controlling for age, gender and duration of illness (Table 5).

Table 1. The prevalence of anxiety and depression in Crohn (CD) and ulcerative colitis (UC)

\begin{tabular}{|c|c|c|c|c|}
\hline \multirow{2}{*}{ Anxiety and depression } & \multicolumn{2}{|c|}{ Crohn } & \multicolumn{2}{|c|}{ Ulcerative colitis } \\
\hline & $\mathrm{N}$ & $\%$ & $\mathrm{~N}$ & $\%$ \\
\hline No & 17 & 39.5 & 37 & $\overline{53.6}$ \\
\hline Anxiety & 5 & 11.6 & 9 & 13.1 \\
\hline Depression & 7 & 16.3 & 4 & 5.8 \\
\hline$A+D$ & 14 & 32.6 & 19 & 27.5 \\
\hline
\end{tabular}

$\chi^{2}=4.323 ; \quad \mathrm{p}=0.229 ; \quad \mathrm{A}=$ anxiety; $\mathrm{D}=$ depression

Table 2. A comparison of anxiety and depression in Crohn (CD) and ulcerative colitis (UC)

\begin{tabular}{lcccccc}
\hline & \multicolumn{3}{c}{ Crohn } & \multicolumn{3}{c}{ Ulcerative colitis } \\
& $\overline{\mathrm{x}}$ & $\mathrm{SD}$ & $\mathrm{x}$ & $\mathrm{SD}$ & $\mathrm{T}$ & $\mathrm{P}$ \\
\hline HAM-A & 15.14 & 8.890 & 13.75 & 6.683 & 0.879 & 0.382 \\
HAM-D & 9.72 & 7.076 & 8.00 & 6.202 & 1.352 & 0.179 \\
\hline
\end{tabular}

$\mathrm{CD}=\mathrm{Crohn} ; \mathrm{UC}=$ ulcerative colitis; HAM-A=Hamilton anxiety rating scale; HAM-D=Hamilton rating test for depression

Table 3. The degree of anxiety and depression in Crohn (CD) and ulcerative colitis (UC)

\begin{tabular}{|c|c|c|c|c|c|c|}
\hline & & & Ulc & olitis & 2 & D \\
\hline & $\mathrm{N}$ & $\%$ & $\mathrm{~N}$ & $\%$ & $\chi$ & $P$ \\
\hline Degree of anxiety & & & & & 5.083 & 0.166 \\
\hline No anxiety & 24 & 55.8 & 41 & 59.4 & & \\
\hline Mild & 2 & 4.7 & 9 & 13.0 & & \\
\hline Moderate & 6 & 14.0 & 11 & 15.9 & & \\
\hline Severe & 11 & 25.6 & 8 & 11.6 & & \\
\hline Degree of depression & & & & & 5.202 & $0.260^{*}$ \\
\hline No depression & 22 & 51.2 & 46 & 66.7 & & \\
\hline Mild & 11 & 25.6 & 10 & 14.5 & & \\
\hline Moderate & 3 & 7.0 & 4 & 5.8 & & \\
\hline Severe & 4 & 9.3 & 8 & 11.6 & & \\
\hline Very severe & 3 & 7.0 & 1 & 1.4 & & \\
\hline
\end{tabular}

Table 4. Correlation index of disease activity with anxiety and depression

\begin{tabular}{lcrrrrrrr}
\hline & \multicolumn{3}{c}{ Baron } & \multicolumn{2}{c}{ Truel\&Witts } & \multicolumn{2}{c}{ SES-CD } & \multicolumn{2}{c}{ CDAI } \\
& $\mathrm{R}$ & \multicolumn{1}{c}{$\mathrm{p}$} & $\mathrm{R}$ & \multicolumn{1}{c}{$\mathrm{p}$} & $\mathrm{R}$ & $\mathrm{p}$ & $\mathrm{R}$ & $\mathrm{p}$ \\
\hline HAM-A & 0.336 & 0.005 & 0.342 & 0.004 & 0.536 & $<0.001$ & 0.395 & 0.009 \\
HAM-D & 0.492 & $<0.001$ & 0.461 & $<0.001$ & 0.425 & 0.004 & 0.399 & 0.008 \\
\hline
\end{tabular}

$\mathrm{SES}-\mathrm{CD}=$ Endoscopic Crohn Disease ndex; $\mathrm{CDAI}=\mathrm{Crohn}$ 's disease activity index; HAM-A=Hamilton anxiety rating scale; HAM-D $=$ Hamilton rating test for depression 
Table 5. Anxiety and depression by age, duration, gender and education

\begin{tabular}{lcccccccc}
\hline & \multicolumn{2}{c}{ Age } & \multicolumn{2}{c}{ Duration of illness } & \multicolumn{2}{c}{ Gender } & \multicolumn{2}{c}{ Education } \\
& $\mathrm{R}$ & $\mathrm{p}$ & $\mathrm{R}$ & $\mathrm{p}$ & $\mathrm{R}$ & $\mathrm{p}$ & $\mathrm{R}$ & $\mathrm{p}$ \\
\hline HAM-A & -0.064 & 0.222 & 0.156 & 0.100 & 0.018 & 0.730 & -0.108 & 0.041 \\
HAM-D & -0.085 & 0.107 & 0.128 & 0.178 & -0.021 & 0.691 & -0.039 & 0.454 \\
\hline
\end{tabular}

HAM-A $=$ Hamilton anxiety rating scale; HAM-D $=$ Hamilton rating test for depression

Table 6. IBD and personality types

\begin{tabular}{|c|c|c|c|c|c|c|}
\hline & \multicolumn{2}{|c|}{ Crohn } & \multicolumn{2}{|c|}{ Ulcerative colitis } & \multirow{2}{*}{$\chi^{2}$} & \multirow{2}{*}{$\mathrm{P}$} \\
\hline & $\mathrm{N}$ & $\%$ & $\mathrm{~N}$ & $\%$ & & \\
\hline Type A/B & & & & & 0.015 & 0.903 \\
\hline A & 28 & 65.1 & 47 & 68.1 & & \\
\hline B & 15 & 34.9 & 22 & 31.9 & & \\
\hline DS14 & & & & & 0.015 & 0.903 \\
\hline $\mathrm{Neg}$ & 28 & 65.1 & 47 & 68.1 & & \\
\hline Pos & 15 & 34.9 & 22 & 31.9 & & \\
\hline
\end{tabular}

Table 7. Index of disease activity and personality types

\begin{tabular}{lcccccccc}
\hline & \multicolumn{2}{c}{ CDAI } & \multicolumn{2}{c}{ SES-CD } & \multicolumn{2}{c}{ Truel\&Witts } & \multicolumn{2}{c}{ Baron } \\
& $\mathrm{R}$ & $\mathrm{p}$ & $\mathrm{R}$ & $\mathrm{p}$ & $\mathrm{R}$ & $\mathrm{p}$ & \multicolumn{1}{c}{$\mathrm{R}$} & $\mathrm{p}$ \\
\hline Type A/B & -0.082 & 0.600 & -0.111 & 0.479 & -0.020 & 0.869 & -0.038 & 0.759 \\
DS14 & 0.084 & 0.592 & 0.132 & 0.398 & -0.058 & 0.637 & 0.052 & 0.673 \\
\hline
\end{tabular}

SES-CD=Endoscopic Crohn Disease ndex; CDAI=Crohn's disease activity index

Table 8. Personality type and anxiety and depression

\begin{tabular}{lcccc}
\hline & \multicolumn{2}{c}{ Type A/B } & \multicolumn{2}{c}{ DS14 } \\
\hline HAM-A & $\mathrm{R}$ & $\mathrm{p}$ & $\mathrm{R}$ & $\mathrm{p}$ \\
HAM-D & -0.171 & 0.001 & 0.310 & $<0.001$ \\
\end{tabular}

HAM-A=Hamilton anxiety rating scale; HAM-D=Hamilton rating test for depression

Table 9. Personality types with age, duration of illness, gender and education

\begin{tabular}{lccrcrrrr}
\hline & \multicolumn{2}{c}{ Age } & \multicolumn{2}{c}{ Duration } & \multicolumn{2}{c}{ Gender } & \multicolumn{3}{c}{ Education level } \\
& $\mathrm{R}$ & $\mathrm{p}$ & $\mathrm{R}$ & $\mathrm{p}$ & $\mathrm{R}$ & $\mathrm{p}$ & $\mathrm{R}$ & $\mathrm{p}$ \\
\hline Tip A/B & 0.099 & 0.059 & -0.117 & 0.218 & 0.080 & 0.127 & -0.001 & 0.988 \\
DS14 & -0.007 & 0.899 & 0.071 & 0.457 & -0.063 & 0.234 & -0.041 & 0.441 \\
\hline
\end{tabular}

\section{Personality types in IBD}

There wasn't found connection between personality type and IBD (Table 6).

There wasn't found relationship between personality types with different indices of monitoring activity of inflammatory bowel disease (Table 7).

IBD patients with $\mathrm{A}$ and $\mathrm{D}$ personality type were found significantly anxious and depressing (Table 8).

There wasn't found connection between personality types with age, duration of illness, gender and education to patients with inflammatory bowel disease (Table 9).

\section{Anxiety and depression in peptic ulcer}

Anxiety was found in $40(32.8 \%)$ patients wih peptic ulcer and depression in $40(32.8 \%)$ patients. When the patients with stomach and duodenal ulcer were analised separately, prevalence of anxiety in stomach ulcer was 54.5\% and depression $50.0 \%$. Prevalence of anxiety in duodenal ulcer was $21.0 \%$ and depression $29.0 \%$ (Table 10 ).
There were no significant differences between stomach and duodenal ulcer in the anxiety and depression values (Table 11).

The levels of anxiety and depression were mild in both stomach and duodenal ulcer patients (Table 12).

\section{Personality types in peptic ulcer}

There wasn't found connection between personality type and ulcer localization (Table 13).

\section{Anxiety and depression in IBD and PU}

The prevalence of anxiety in the control group was $16.4 \%$ and $15.6 \%$ depression.

In patients with IBD prevalence of anxiety was $40.1 \%$, and in patients with peptic ulcer $33.6 \%$. The prevalence of depression in patients with IBD to a $38.3 \%$, and in patients with ulcer $27.1 \%$ (Table 14). This indicates that the prevalence of anxiety and depression more increased in IBD than in psychosomatic disease that is peptic ulcer. 
Table 10. The prevalence of anxiety and depression in the ulcer

\begin{tabular}{|c|c|c|c|c|}
\hline \multirow{3}{*}{ Anxiety and depression } & \multicolumn{4}{|c|}{ Ulcer } \\
\hline & \multicolumn{2}{|c|}{ Stomach } & \multicolumn{2}{|c|}{ Duodenum } \\
\hline & $\mathrm{N}$ & $\%$ & $\mathrm{~N}$ & $\%$ \\
\hline No & 8 & 36.4 & 61 & 61.0 \\
\hline Anxiety & 3 & 13.6 & 10 & 10.0 \\
\hline Depression & 2 & 9.1 & 11 & 11.0 \\
\hline$A+D$ & 9 & 40.9 & 18 & 18.0 \\
\hline
\end{tabular}

$\chi^{2}=6.330 ; \quad \mathrm{p}=0.081$ (Fisher test); $\mathrm{A}=$ anxiety; $\mathrm{D}=$ depression

$\underline{\text { Table 11. Ulcer location with anxiety and depression }}$

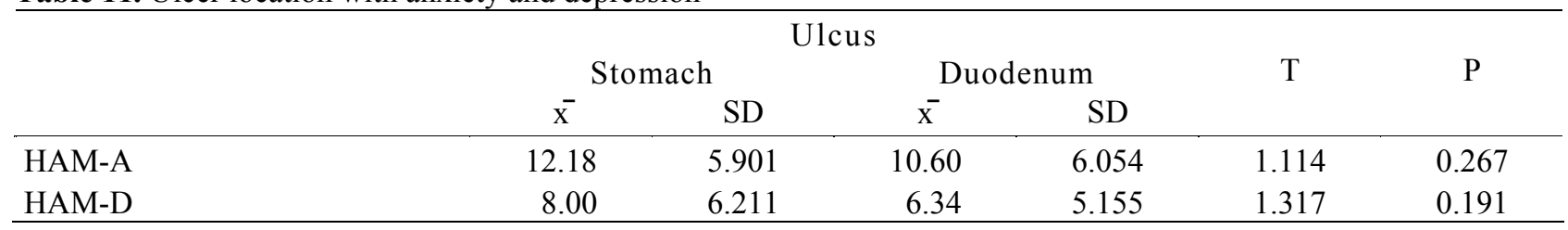

HAM-A=Hamilton anxiety rating scale; HAM-D=Hamilton rating test for depression

Table 12. The degree of anxiety and depression in the ulcer

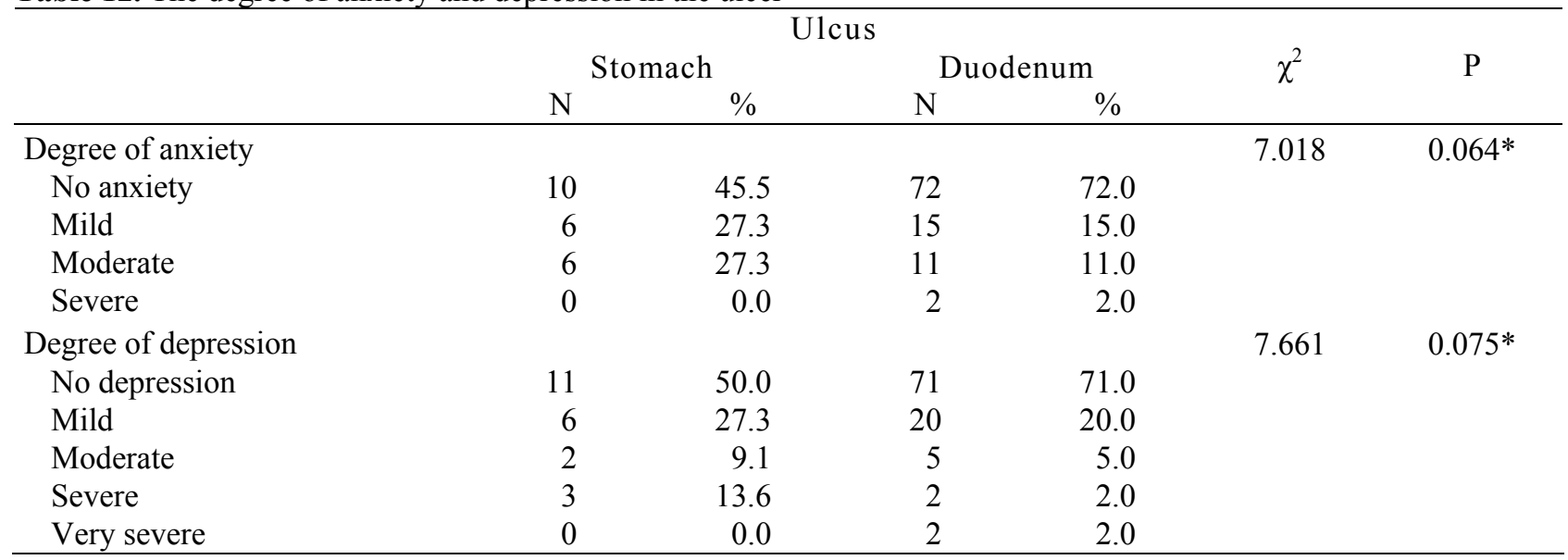

* Fisher test

Table 13. Ulcer localization and personality types

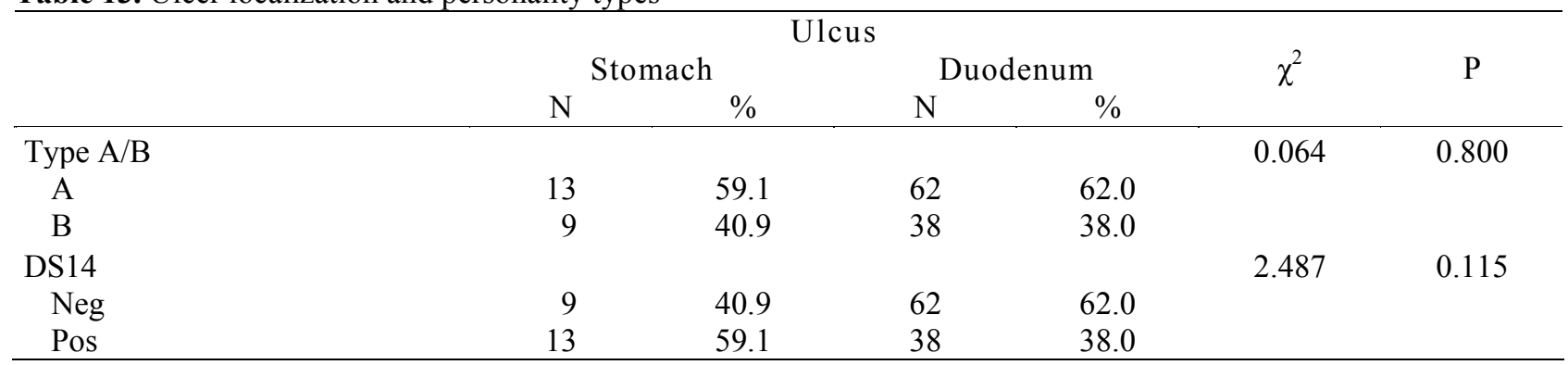

Table 14. The degree of anxiety and depression in IBD and ulcers

\begin{tabular}{lcccccc}
\hline \multirow{2}{*}{ Anxiety and depression } & \multicolumn{2}{c}{ IBD } & \multicolumn{3}{c}{ Group } \\
& $\mathrm{N}$ & $\%$ & $\mathrm{~N}$ & $\%$ & \multicolumn{2}{c}{ Control } \\
\hline No & 54 & 48.2 & 72 & 59.0 & 98 & 76.6 \\
Anxiety & 15 & 13.4 & 17 & 13.9 & 10 & 7.8 \\
Depression & 13 & 11.6 & 9 & 7.4 & 9 & 7.0 \\
A + D & 30 & 26.8 & 24 & 19.7 & 11 & 8.6 \\
\hline
\end{tabular}

$\chi^{2}=23.542 ; \mathrm{df}=6 ; \mathrm{p}=0.001 ; \mathrm{IBD}=$ Inflammatory Bowel Disease 
Table 15. Comparison of anxiety and depression in UBC and ulcer

\begin{tabular}{lcccccccc}
\hline & $\overline{\mathrm{x}}$ & $\mathrm{IBD}$ & $\overline{\mathrm{x}}$ & $\mathrm{SD}$ & $\overline{\mathrm{x}}$ & Control & \multirow{2}{*}{$\mathrm{F}$} & \multirow{2}{*}{$\mathrm{P}$} \\
\hline HAM-A & 14.29 & 7.597 & 10.89 & 6.033 & 8.49 & 6.510 & 22.311 & $<0.001$ \\
HAM-D & 8.66 & 6.574 & 6.64 & 5.371 & 4.76 & 5.435 & 13.571 & $<0.001$ \\
\hline
\end{tabular}

HAM-A=Hamilton anxiety rating scale; HAM-D=Hamilton rating test for depression; IBD=Inflammatory Bowel Disease

Table 16. Multiple comparison Scheffe test

\begin{tabular}{lllr}
\hline & Group & & P \\
\hline \multirow{2}{*}{ HAM-A } & IBD & Ulcer & 0.001 \\
& & Control & $<0.001$ \\
& Ulcer & IBD & 0.001 \\
& \multirow{3}{*}{ Control } & Control & 0.020 \\
& & IBD & $<0.001$ \\
& IBD & Ulcer & 0.020 \\
& \multirow{2}{*}{ Ulcer } & Ulcer & 0.030 \\
& HAM-D & Control & $<0.001$ \\
& Control & IBD & 0.030 \\
& Control & 0.038 \\
& & IBD & $<0.001$ \\
\hline
\end{tabular}

HAM-A=Hamilton anxiety rating scale; HAM-D=Hamilton rating test for depression; IBD=Inflammatory Bowel Disease

Table 17. Personality types of inflammatory bowel disease and ulcer

\begin{tabular}{|c|c|c|c|c|c|c|c|c|}
\hline & \multicolumn{6}{|c|}{ Group } & \multirow{3}{*}{$\chi^{2}$} & \multirow{3}{*}{$\mathrm{P}$} \\
\hline & \multicolumn{2}{|c|}{ IBD } & \multicolumn{2}{|c|}{ Ulcer } & \multicolumn{2}{|c|}{ Control } & & \\
\hline & $\mathrm{N}$ & $\%$ & $\mathrm{~N}$ & $\%$ & $\mathrm{~N}$ & $\%$ & & \\
\hline Type A/B & & & & & & & 1.303 & 0.521 \\
\hline A & 75 & 67.0 & 75 & 61.5 & 77 & 60.2 & & \\
\hline B & 37 & 33.0 & 47 & 38.5 & 51 & 39.8 & & \\
\hline Type D & & & & & & & 14.681 & 0.001 \\
\hline $\mathrm{Neg}$ & 75 & 67.0 & 71 & 58.2 & 103 & 80.5 & & \\
\hline Pos & 37 & 33.0 & 51 & 41.8 & 25 & 19.5 & & \\
\hline
\end{tabular}

HAM-A=Hamilton anxiety rating scale; HAM-D=Hamilton rating test for depression; IBD=Inflammatory Bowel Disease

Multiple comparison, we found a significantly higher anxiety and depression in UBC than in ulcer or control group, and anxiety and depression were significantly higher in ulcer than the control group (Table 15, Table 16).

\section{Personality types in IBD and PU}

D personality type is statistically the most significant present in patients with ulcer disease. Type A personality is more commonly found in $\mathrm{UBC}$ and ulcer than Type B personalities, but indicated no statistically significant difference (Table 17).

\section{DISCUSSION}

\section{Anxiety and depression in the IBD}

In the total of 112 IBD patient, anxiety were found in $47(41.9 \%)$ and depression in $44(39.3 \%)$ patients. Prevalence of anxiety in control group was $16.4 \% \%$ and depression $15.6 \%$. That confirms some earlier studies which showed that the prevalence of anxiety and depression is greater in patients with IBD than in the general population (Walker 2008). But there are studies whose results were different regarding the presence of anxiety and depression in patients with IBD and their impact on the course of the disease. The study of Simréna found the presence of anxiety and depression in patients with ulcerative colitis and Crohn's disease was similar to the general population (Simren 2002). Analyzing the results relate to Crohn's disease, we determined the prevalence of anxiety and depression $44.1 \%$ from $48.8 \%$. This is in line with the results of some previous studies that found the prevalence of anxiety in Crohn's disease by $30-50 \%$ and depression about 50\% (Lima 2012, Bryant 2011). Keller's German studies didn't find the connection between Crohn's disease and significant presence of anxiety and depression (Keller 2004). Female and male patients and CD and UC patients did not differ in anxiety and depression.

Our study confirms the association of disease activity and anxiety and depression. The association is probably bidirectional. 
Worsening symptoms initiate negative thoughts and emotions in patients, and stressful events that were followed anxiety and depression can be a trigger for the worsening of the underlying disease (Duffy 1991, Sewitch 2001, Addolorato 1997). Some studies have confirmed that most stressful event can trigger the worsening of clinical status in patients with UBC (Woodward 2016). The mechanism in which stress can affect the worsening of symptoms and course of the disease is multiple. Stress stimulates the release of corticotropin-releasing factor (Corticotropin-releasing factor, CRF) from the central and peripheral parts of the nervous system. Peripheral CRF directly affects the digestive system by stimulating bowel motility (296). Acting on the cholinergic system functions and mucosal cells of the intestine in an increased permeability, stimulation of secretion of ions, water, mucus, and IgA that results in reduced mucosal barriers and creating a suitable environment for the growth of bacteria (Hollander 2003, Kuroki 2007).

Proinflammatory cytokines play a crucial role in the pathogenesis of UBC. It is an essential principle of action of biological therapies in blocking the proinflammatory cytokines (Roda 2011). There are series of studies which confirm that psychological distress may increase the level of pro-inflammatory cytokines (IL$1 \beta$, IL6, IL10, IL4, and TNF) which contribute to the pathophysiology in the UBC. This may be an explanation why the active disease in our patients often present anxiety and depression (Langhorst 2007, Bernstein 2010).

We found that the level of anxiety significantly higher in our IBD patients with low 1 levels of education as confirmed by Dressman research and associates who have also found a higher level of anxiety in IBD patients who had a lower level of education (Drossman 1991).

If the disease occurs in childhood, can have a negative impact on normal training and eduction of which may result in a lower level of education (Moody 1999, Calsbeek 2002). On the other hand, is better informed about the disease, which is more common in educated people, can reduce feelings of anxiety and depression (Wardle 2014). The determination of the significance of education and economic factors and their relation to anxiety and depression in IBD deserves further research.

Depression increases the sensitivity to abdominal pain. In patients with marked anxiety and depression there is greater use of analgesics, including opioids. Depressed patients often do not adhere to taking the prescribed therapy, which can have negative and lasting effects on the health status (Cook 2014, Goodhand 2013). Anxiety IBD patients with receiving biological treatments are more likely to irregular arrivals in the administration of therapy than those without anxiety. This indicates a direct connection between anxiety and depression to regularly receive therapy (,compliance") and possible negative outcome of treatment of disease (Lopez 2013).

Regular endoscopic control are necessary for monitoring activities and complications. Anxiety patients have a much lower tolerance to endoscopic examination leading to a failure to implement controls. In the long term may have adverse consequences in increased levels of disease complications such as stricture, perforation and cancer (Bessissow 2013).

Psychotherapy can have a positive effect on reducing pain, excessive medication, relapse, hospitalization and compliance (Knowles 2013). There is a need for further cooperation between gastroenterologists and psychiatrists to achieve consensus on therapeutic approach to the IBD in order to achieve a higher level of treatment success.

\section{Personality types in the IBD}

There was no statistically significant correlation between $\mathrm{A} / \mathrm{B}$ or $\mathrm{D}$ type personalities in our $\mathrm{CB}$ and $\mathrm{UC}$ patients. Type A personality was twice as common in $\mathrm{CB}$ and UC, but not statistically significant. One of the characteristics of A type of personality is the tendency to worry and anxiety. IBD patients with worry and anxiety may have a higher risk for severe disease course (Hyphantis 2010).

\section{Anxiety and depression in peptic ulcer}

Anxiety and stress can be the most important factor in the development and complications of petic ulcer. Psychiatric supportive treatment of anxiety and depressive patients in combination with anti-ulcer drug provides more effective treatment of PU but only therapeutic approach to anti-ulcer medication (Wu 2012). No gender differences in anxiety and depression could be found in our peptic ulcer patients.

\section{Specifics of patients with IBD and peptic ulcer}

Our research shows that anxiety and depression are significantly more frequent in IBD than in PU and anxiety and depression are more common in PU than in the general population. The complexity of the disease in the IBD, the severe symptoms of the disease, but also overlapping pathophysiological pathways, leading to pronounced psychological distress in these patients, even greater than in psychosomatic diseases as the PU (Goodwin 2013).

\section{Personality types of peptic ulcer}

We found a statistically significant presence of type $\mathrm{D}$ personality in peptic ulcer. D personality type shows significant affinity for the anxiety and depression. Anxiety and depression are significantly participating in the pathomechanism of PU (Pedersen 2004). 


\section{CONCLUSION}

Our research has found that anxiety and depression are directly correlated with the severity of the clinical condition of the IBD and affect the course of the disease, which indicates the necessity of reducing their harmful effects. At the time of diagnosis IBD would be necessary to verify the degree of anxiety and depression in each patient as a standard measure.

This indicates the necessity of including a psychiatrist and psychiatric support team for IBD which is not the case in a regular practice in Bosnia and Herzegovina, the region and a number of European countries. This would be a positive effect on the course of the disease, a small number of complications, a better therapeutic response, decrease the frequency of relapse and prolonging remission.

\section{Acknowledgements: None.}

Conflict of interest: None to declare.

\section{Contribution of individual authors:}

Emil Babić, Milenko Bevanda \& Danijel Bevanda involved in the concept and design of the survey;

Emil Babić, Maja Karin, Mile Volarić, Ante Bogut \& Daniela Bevanda Glibo collected, assembled, analysed and interpreted the data;

Danijel Bevanda \& Nikica Šutalo critically reviewed and edited the manuscript. All authors have approved the final version of the article, including the authorship list.

Emil Babić accepts responsibility for the integrity of the work as a whole from inception to the published article.

\section{References}

1. Addolorato G, Capristo E, Stefanini GF, Gasbarrini G: Inflammatory bowel disease: a study of the association between anxiety and depression, physical morbidity, and nutritional status. Scandinavian Journal of Gastroenterology 1997; 32:1013-21

2. Bernstein N, Singh S, Graff LA, Walker JR, Miller N, Cheang M: A prospective population-based study of triggers of symptomatic flares in IBD. American Journal of Gastroenterology 2010; 105:1994-2002

3. Bessissow T, Van Keerberghen CA, Van Oudenhove L, Ferrante M, Vermeire S, Rutgeerts P: Anxiety is associated with impaired tolerance of colonoscopy preparation in inflammatory bowel disease and controls. J Crohns Colitis 2013; 7:580-7

4. Bryant RV, van Langenberg DR, Holtmann GJ, Andrews JM: Functional gastrointestinal disorders in inflammatory bowel disease: impact on quality of life and psychological status. J Gastroenterol Hepatol 2011; 26:916-23

5. Calsbeek H, Rijken M, Bekkers MJ, Kerssens JJ, Dekker J, van Berge Henegouwen GP: Social position of adoles- cents with chronic digestive disorders. Eur J Gastroenterol Hepatol 2002; 14:543-9

6. Cook SF, Allen JK, Kappelman MD: Prevalence of Chronic Narcotic Use Among Children With Inflammatory Bowel Disease. Clin Gastroenterol Hepatol 2014; pii: S1542-3565(14)01142-2.

doi: $10.1016 / j . c g h .2014 .07 .057$

7. Drossman DA, Leserman J, Li ZM, Mitchell CM, Zagami EA, Patrick DL: The rating form of IBD patient concerns: a new measure of health status. Psychosom Med 1991; 53:701-12

8. Duffy LC, Zielezny MA, Marshall JR, Byers TE, Weiser MM, Phillips JF: Relevance of major stress events as an indicator of disease activity prevalence in inflammatory bowel disease. Behav Med 1991; 17:101-10

9. Goodhand JR, Kamperidis N, Sirwan B, Macken L, Tshuma N, Koodun Y: Factors associated with thiopurine non-adherence in patients with inflammatory bowel disease. Aliment Pharmacol Ther 2013; 38:1097-108

10. Goodwin RD, Talley NJ, Hotopf M, Cowles RA, Galea S, Jacobi F: A link between physician-diagnosed ulcer and anxiety disorders among adults. Ann Epidemiol 2013; 23:189-92

11. Graff LA, Walker JR, Bernstein CN. Depression and anxiety in inflammatory bowel disease: a review of comorbidity and management. Inflamm Bow Dis 2009; 15:1105-18

12. Hollander D: Inflammatory bowel diseases and brain-gut axis. Journal of Physiology and Pharmacology 2003; 54:183-90

13. Hyphantis T, Antoniou $K$, Tomenson B, Tsianos E, Mavreas $V$, Creed $F$ : Is the personality characteristic "impulsive sensation seeking" correlated to differences in current smoking between ulcerative colitis and Crohn's disease patients? Gen Hosp Psychiatry 2010; 32:57-65

14. Jakovljević $M \&$ Ostojić L: Comorbidity and multimorbidity in medicine today: challenges and opportunities for bringing separated branches of medicine closer to each other. Psychiatr Danub 2013; 25:18-28

15. Jakovljević $M$ \& Ostojić L: Person-centered medicine and good clinical practice: disease has to be cured, but the patient has to be healed. Psychiatr Danub 2015; 2:546-9

16. Keller W, Pritsch M, Von Wietersheim J, Scheib P, Osborn $W$, Balck F: Effect of psychotherapy and relaxation on the psychosocial and somatic course of Crohn's disease: main results of the German Prospective Multicenter Psychotherapy Treatment study on Crohn's Disease. J Psychosom Res 2004; 56:687-96

17. Knowles SR, Monshat K, Castle DJ: The efficacy and methodological challenges of psychotherapy for adults with inflammatory bowel disease: a review. Inflamm Bowel Dis 2013; 19:2704-15

18. Kuroki T, Ohta A, Aoki Y: Stress maladjustment in the pathoetiology of ulcerative colitis. Journal of Gastroenterology 2007; 42:522-27

19. Langhorst J, Cobelens PM, Kavelaars A: Stress-related peripheral neuroendocrine-immune interactions in women with ulcerative colitis. Psychoneuroendocrinology 2007; 32:1086-96

20. Lima FD, Ribeiro TC, Chebli LA, Pace FH, Chaves LD, Ribeiro MS: Mood swings in patients with Crohn's disease: incidence and associated factors.Rev Assoc Med Bras 2012; 58:481-8 
21. Lopez A, Billioud V, Peyrin-Biroulet C, Peyrin-Biroulet L: Adherence to anti-TNF therapy in inflammatory bowel diseases: a systematic review. Inflamm Bowel Dis 2013; 19:1528-33

22. Mikocka-Walus AA, Turnbull DA, Moulding NT, Wilson $I G$, Andrews JM, Holtmann G: Controversies surrounding the comorbidity of depression and anxiety in inflammatory bowel disease patients: a literature review. Inflamm Bowel Dis 2007; 13:225-34

23. Moody G, Eaden JA, Mayberry JF: Social implications of childhood Crohn's disease. J Pediatr Gastroenterol Nutr 1999; 28:43-5

24. Pedersen SS, van Domburg RT, Theuns DA, Jordaens L, Erdman RA: Type D personality is associated with increased anxiety and depressive symptoms in patients with an implantable cardioverter defibrillator and their partners. Psychosom Med 2004; 66:714-9

25. Porcelli P, Leoci C, Guerra V: A prospective study of the relationship between disease activity and psychologic distress in patients with inflammatory bowel disease. Scand J Gastroenterol 1996; 31:792-6

26. Roda G, Marocchi Sartini A, Roda E: Cytokine networke in ulcerative colitis. Ulcers 2011; 2011:5

27. Sewitch MJ, Abrahamowicz M, Bitton A, Daly D, Wild GE, Cohen A: Psychological distress, social support, and disease activity in patients with inflammatory bowel disease.Am J Gastroenterol 2001; 96:1470-9

28. Simrén M, Axelsson J, Gillberg R, Abrahamsson $H$, Svedlund J, Björnsson ES: Quality of life in inflammatory bowel disease in remission: the impact of IBS-like ymptoms and associated psychological factors. Am J Gastroenterol 2002; 97:389-96

29. Walker JR, Ediger JP, Graff LA, Greenfeld JM, Clara I, Lix L: The Manitoba IBD cohort study: a populationbased study of the prevalence of lifetime and 12-month anxiety and mood disorders. Am J Gastroenterol. 2008; 103:1989-97

30. Wardle RA \& Mayberry JF: Patient knowledge in inflammatory bowel disease: the Crohn's and Colitis Knowledge Score. Eur J Gastroenterol Hepatol 2014; 26:1-5

31. Woodward S, Dibley L, Coombes S, Bellamy A, Clark C, Czuber-Dochan W: Identifying disease-specific distress in patients with inflammatory bowel disease. $\mathrm{Br} J$ Nurs. 2016; 25:649-60

32. Wu DY, Guo M, Gao YS, Kang YH, Guo JC, Jiang XL: Clinical effects of psychological intervention and drug therapy against peptic ulcer. Asian Pac J Trop Med 2012; 5:831-3

Correspondence:

Emil Babić, MD

University of Mostar Clinical Hospital, Department of Gastroenterology and Hepatology

Bijeli Brijeg bb, 88000 Mostar, Bosnia and Herzegovina

E-mail:emil.babic@yahoo.com 